\title{
Causes of childhood blindness in Sri Lanka: results from children attending six schools for the blind
}

\author{
M B Eckstein, A Foster, C E Gilbert
}

\begin{abstract}
Aim-The survey aimed to identify the major treatable or preventable causes of visual loss in children attending blind schools in Sri Lanka so that appropriate control measures can be implemented.

Method-A total of 226 children with blindness (BL) or severe visual impairment (SVI) attending six schools for the blind were examined and details recorded using the WHO standard reporting form.

Results-Cataract was responsible for $17 \%$ of BL/SVI and was the commonest 'avoidable' cause of childhood blindness. Bilateral microphthalmos accounted for one quarter of BL/SVI. Vitamin A deficiency was not a significant cause of visual morbidity.

Conclusion-The pattern of childhood blindness seen in this study is typical of a growing number of south east Asian countries which are developing rapidly. Childhood cataract is a major avoidable cause that can benefit from future intervention strategies.

(Brf Ophthalmol 1995; 79: 633-636)
\end{abstract}

Childhood blindness has profound consequences not only for the individual child but also for the family and the community. This is particularly true in the developing world. An estimated 1.5 million children are blind of whom 1 million live in Asia. ${ }^{1}$ This accounts for approximately 75 million years of blindness which is similar to the visual morbidity from unoperated adult cataract. ${ }^{2}$

The WHO has developed a standard reporting form to document the causes of visual loss in children with emphasis being placed on the identification of avoidable causes of blindness. ${ }^{3}$

Sri Lanka which is situated just south of the Indian subcontinent is a developing country with a population of 17.9 million people of which 5.8 million are under 15 years old. The population is made up of $72 \%$ Sinhalese living predominantly in the centre and south of the island and $20 \%$ Tamil who live in the north and east. The country has a high literacy rate $(89 \cdot 1 \%)$ and a well informed population. There are no data on the causes of blindness among children from Sri Lanka.

This study was undertaken to:

(1) Assess requirements of individual children attending blind schools for medical, surgical, or optical treatment.
(2) Identify the major preventable or treatable reasons for loss of vision in blind schoolchildren so that appropriate control measures could be implemented in the future.

(3) Provide baseline data to allow monitoring of the changing diseases causing admission to schools for the blind over time in response to changes in health care, specific interventions, and socioeconomic development.

\section{Subjects and methods}

A total of 255 children aged between 6-15 years attending six schools for the blind were examined. Four of the six schools were for both deaf and blind children. Civil unrest made it impractical to visit another school in the north of the country. In Sri Lanka about 450 children with visual impairment presently attend normal schools under a continuing integrated education programme. These children are spread throughout the country and were not examined.

All children at the blind schools were examined but only those 15 years of age or under have been analysed for this study. Children were asked with the aid of an interpreter the age at which they lost vision, whether they knew the cause of their poor vision, and whether there was any relevant family history including a history of consanguinity. Limited past medical history was available from the school records. Visual acuity was measured using an Illiterate $\mathrm{E}$ chart or the Sheridan Gardner test by a single trained observer. All children were refracted where possible, and the visual acuity repeated with correction. Visual loss was classified according to the WHO categories of visual impairment. An assessment of functional vision was made on all children. This tested ability to walk around furniture unaided, to recognise faces, and to see large print.

Anterior segment examination was performed with a torch and magnifying loupe. Posterior segment examination was undertaken after dilating the pupil, using a direct and indirect ophthalmoscope. Intraocular pressure was not measured routinely. Examinations were performed by one ophthalmologist (ME). All data were recorded on the WHO/PBL eye examination record for children with blindness and low vision and entered into a customised database using a portable computer. ${ }^{3}$ Children who required further assessment and treatment were referred to a designated ophthalmologist at a government eye hospital. 
Table 1 Categories of visual loss in 255 Sri Lankan children attending blind schools

\begin{tabular}{llc}
\hline WHO category & Level of vision & No $(\%)$ \\
\hline No impairment & $\geqslant 6 / 18$ & $8(3 \cdot 1)$ \\
Visual impairment & $<6 / 18-6 / 60$ & $20(7 \cdot 8)$ \\
Severe visual impairment & $<6 / 60-3 / 60$ & $45(17 \cdot 7)$ \\
Blind & $<3 / 60-$ NPL & $181(71 \cdot 0)$ \\
Cannot test & & $1(0 \cdot 4)$ \\
Total & & $255(100)$ \\
\hline
\end{tabular}

\section{Results}

Of the children examined $181(71 \%)$ were blind (best VA <3/60), $45(18 \%)$ had severe visual impairment (best VA $<6 / 60-3 / 60$ ), 20 $(8 \%)$ had visual impairment (best VA $<6 / 18-6 / 60)$, and eight (3\%) had normal vision (Table 1). Of those children who were blind (BL) or severely visually impaired (SVI), $114(50 \cdot 4 \%)$ had navigational vision, being able to walk unaided between two chairs placed 1 metre apart in a well lit room.

The total number of male and female children examined were equal (male 50.4\%). The majority of children ( $72 \%$ ) were between 10 and 15 years old. Many younger children now attend schools in the integrated education programme, and those children who would be better placed in blind schools are often delayed by competition for places and lack of awareness by patients.

The vast majority of children were ethnically Sinhalese $(98 \%)$ owing mainly to the geographical distribution of the schools.

ANATOMICAL CAUSE OF VISUAL LOSS (TABLE 2)

Whole globe

Bilateral microphthalmos was the commonest cause of BL/SVI $(26 \%)$. This was associated with uveal and/or retinal colobomas in a quarter of the cases. Other anomalies of the globe (anophthalmos, phthisis) accounted for a further $10 \%$ of all cases.

\section{Cornea}

Corneal scarring definitely attributable to vitamin A deficiency was seen in only four children $(2 \%)$.

\section{Lens}

Cataract was responsible for $39(17 \%)$ children being BL/SVI. Uncorrected aphakia

Table 2 Anatomical site of abnormality leading to severe visual impairment and blindness in $226 \mathrm{Sri}$ Lankan children attending blind schools

\begin{tabular}{lc}
\hline $\begin{array}{l}\text { Site of } \\
\text { abnormality }\end{array}$ & No (\%) \\
\hline Whole globe & $81(35 \cdot 8)$ \\
Cornea & $5(2 \cdot 2)$ \\
Lens & $39(17 \cdot 3)$ \\
Retina & $50(22 \cdot 1)$ \\
Optic nerve & $17(7 \cdot 5)$ \\
Glaucoma & $13(5 \cdot 8)$ \\
Other & $21(9 \cdot 3)$ \\
Total & $226(100)$ \\
\hline
\end{tabular}
usually with amblyopia accounted for 18 (46\%), unoperated cataracts for $17(44 \%)$, and complications of cataract surgery for four $(10 \%)$ of the lenticular causes.

\section{Retina}

Retinal disease was the second most common cause of visual loss accounting for $50(22 \%)$ retinal dystrophies which included three cases of Usher's disease and 12 cases of Leber's amaurosis. There was no case of retinopathy of prematurity. cases of BL/SVI. The majority was due to
Table 3 Aetiological categories in 226 Sri Lankan children attending blind schools with severe visual impairment and blindness

\begin{tabular}{lc}
\hline Aetiological category & No (\%) \\
\hline Hereditary disease & $79(35 \cdot 0)$ \\
Intrauterine factor & $8(3 \cdot 5)$ \\
Perinatal factor & $0(0 \cdot 0)$ \\
Childhood factor & $12(5 \cdot 3)$ \\
Unknown & $127(56 \cdot 2)$ \\
Total & $226(100)$ \\
\hline
\end{tabular}

Optic nerve

Primary optic atrophy was responsible for 16 $(7 \%)$ cases of BL/SVI and one quarter of these were hereditary. Bilateral optic hypoplasia was responsible for one case of visual loss.

\section{Glaucoma}

There were $15(6 \%)$ children with visual loss due to congenital glaucoma or buphthalmos. Drainage surgery had been performed on two of the children. In four cases there was a positive family history, a sibling being similarly affected. In three of these cases the parents were first cousins. There was a single case of secondary glaucoma due to hereditary spherocytosis.

AETIOLOGY OF VISUAL LOSS (TABLE 3)

Hereditary disease was responsible for at least $35 \%$ of BL/SVI. Most of this was due to retinal dystrophy, cataract, and optic atrophy. Intrauterine factors such as congenitally acquired rubella could only be incriminated in $3 \%$ of cases. Perinatal factors such as retinopathy of prematurity (ROP) and ophthalmia neonatorum were not seen. The majority of children had disorders of unknown aetiology (56\%). This included microphthalmos, anophthalmos, buphthalmos, and cataract which could not be attributed to hereditary disease or specific factors occurring during the intrauterine period.

\section{Discussion}

Reliable information on the causes of visual loss in children is difficult to obtain in areas of the world where there is no system of blindness registration. Examination of children in blind schools can provide this information relatively easily but is limited and cannot be used to calculate cause specific prevalence data. Not all blind children are admitted to blind schools, those with additional disabilities such as mental or physical handicap or those from poor rural communities are likely to be underrepresented. Preschool age children are also not represented.

Given an estimated prevalence of childhood blindness of 0.5 per 1000 children, ${ }^{4}$ there will be approximately 2900 blind or severely visually impaired children in Sri Lanka. It is known that there are approximately 300 children in seven schools for the blind (the present study examined 255 in six of these schools), a further estimated 450 in integrated education and therefore more than 
Table 4 Proportion of childhood blindness due to cataract in blind school surveys

\begin{tabular}{ll}
\hline Country (ref) & $\% B L / S V I$ \\
\hline Chile (10) & 7 \\
Zimbabwe (12) & 7 \\
West Africa (9) & 10 \\
Cyprus (8) & 11 \\
India (4) & 12 \\
Philippines (13) & $10-17$ \\
Thailand (13) & 17 \\
\hline
\end{tabular}

2000 who are not in a formal education programme. For logistic reasons it was not possible to trace individual children in integrated education. The approximate $10 \%$ sample examined in this study must therefore be viewed as a selected group having a bias towards older children, probably from more affluent households and in whom visual loss is likely to be more severe.

There has been no previous survey of blind schoolchildren in Sri Lanka. Until recently there has been difficulty comparing data from different studies as different definitions and systems of classification have been used. The recently published classification and recording system for the WHO allows cross sectional and longitudinal comparison of data on the causes of blindness and low vision in children. ${ }^{3}$

A recent study of $1318 \mathrm{BL} / \mathrm{SVI}$ children in India ${ }^{5}$ using the same reporting form found a very different spectrum of disease compared with this study. Vitamin A deficiency related blindness is unusual in Sri Lanka and was found only in one specific focal area populated by Tamil workers who live on tea estates. There was no nutritional blindness seen among the Sinhalese population. This is in contrast with India where $19 \%$ of all cases of BL/SVI in children were the result of vitamin A deficiency. The blinding form of vitamin A deficiency most often occurs between 1 and 3 years of age as children are weaned onto diets severely deficient in vitamin A. Sri Lanka with minimal nutritional blindness has a similar pattern of childhood blindness to countries of the developed world where the majority of childhood blindness is congenital or occurs within the first year of life. ${ }^{6}$

Hereditary diseases of the retina, lens, and optic nerve accounted for $35 \%$ of BL/SVI in Sri Lanka and $23 \%$ in India. This higher proportion is similar to reports from blind schools in developed countries. ${ }^{7}$ Genetic disease tends to be responsible for a lower proportion of visual loss in the poorer less developed countries of the world where nutritional and infectious causes of childhood blindness predominate. Autosomal recessive disease is common in the east Mediterranean region and has been attributed to the high level of consanguineous marriage. ${ }^{89}$ In Sri Lanka about one quarter of marriages are consanguineous (first cousin, uncle/niece). Approximately half of the children with visual loss due to retinal dystrophy had parents who were closely related.

The commonest cause of visual loss in this study was because of congenital ocular anomalies such as microphthalmos and anophthalmos. These accounted for $33 \%$ of all children with BL/SVI. This figure is similar to the $25 \%$ reported in India, ${ }^{5}$ but higher than that from other blind school surveys using the same reporting form; west Africa $6 \%$, Chile $7 \% .^{1011}$ Known causes of microphthalmos include genetic disease, viral infections during pregnancy, and teratogenic drugs. In this study it was not possible to determine the aetiology of ocular malformations but this is an area of work which would justify future research.
Childhood cataract was responsible for $16 \%$ of BL/SVI, one third of which was hereditary. Nearly half the children had unoperated cataracts and the remainder had severe visual loss from amblyopia, failure of optical correction, or surgical complications. Childhood cataract is the leading cause of surgically correctable blindness in most countries in the developing world (Table 4). Unfortunately the children are often brought late with nystagmus and/or amblyopia. Aphakic glasses may not be available or replaceable, and regular follow up is difficult to maintain. A prospective study of visual outcome following cataract surgery is under way in south India and this may help in deciding on future intervention strategies in developing countries.

Congenital glaucoma was responsible for $6 \%$ of BL/SVI. This is similar to the figures reported for other developing countries. 5611 Approximately one quarter of cases were familial, and in others the aetiology could not be determined. Only two of the 15 children with glaucoma had received surgical treatment.

Retinopathy of prematurity was not seen. Neonatal intensive care facilities are now becoming available in Sri Lanka and it is likely that cases will begin to occur soon. ROP is increasingly being seen in the more developed countries of Latin America and its appearance ironically may be an indicator of improved health care. ${ }^{11}$

\section{Conclusions}

Prevention of childhood blindness is an important component of any child or eye care service whether it is considered in economic, social, or health terms. Approximately $75 \%$ of all childhood blindness in developing countries is preventable or curable. ${ }^{1}$ The poorer the country the larger the pool of preventable disease. Sri Lanka is a small country with good communications, a high literacy rate, and low population growth $(1 \%)$. It is one of a growing number of south east Asian countries which are developing rapidly and the pattern of childhood blindness reflects this situation:

(1) Cataract is the commonest 'avoidable' cause of childhood blindness in blind schoolchildren. Half the children have unoperated cataract, and the other half have amblyopia from late or inadequate surgery and aphakic correction.

(2) Hereditary disease of the retina, lens, and optic nerve is responsible for one third of all admissions to blind school with first cousin and uncle/niece marriages probably a relevant factor.

(3) Vitamin A deficiency is seen rarely and only in certain Tamil tea picking communities.

(4) Microphthalmos/anophthalmos accounts for one quarter of cases, but the aetiology is at present unknown.

This study was supported by a grant from the Tijssen foundation, Netherlands. The authors thank Dr C R Seimon for his support. 
1 World Health Organisation. Prevention of childhood blindness. Geneva: WHO, 1992.

2 Foster A. Worldwide blindness, increasing but avoidable. Semin Ophthalmol 1993; 8: 166-70.

3 Gilbert C, Foster A, Negrel A, Thylefors B. Childhood blindness: a new form for recording causes of visual loss in children. Bull World Health Org 1993; 71: 485-9.

4 Workshop on childhood blindness in S Asia. Aravind Eye Hospital, 1994.

5 Rahi J, Foster A, Gilbert C. Causes of childhood blindness in India. Eye 1995 (in press)

6 Foster A, Gilbert C. Epidemiology of childhood blindness. Eye 1992; 6: 173-6.

7 Rosenberg T, Flage T, Hansen E, Rudanko S, Viggosson G, Riise R. Visual impairment in Nordic children. Acta $155-64$

8 Elder MJ, De Cock R. Childhood blindness in the West
Bank and Gaza Strip: prevalence, aetiology and hereditary factors. Eye 1993; 7: 580-3.

9 Merin S, Lapithis AG, Horovitz D, Michaelson IC Childhood blindness in Cyprus. An $\mathcal{f}$ Ophthalmol 1972; 74: 538-42.

10 Gilbert C, Canovas R, Hagan M, Rao S, Foster A. Causes of childhood blindness: results from West Africa, South India and Chile. Eye 1993; 17: 184-8.

11 Gilbert C, Canovas R, Kocksch de Canovas R, Foster A. Causes of blindness and severe visual impairment in children in Chile. Devel Child Neurol 1994; 36: 326-33.

12 Schwab L Kame K Blindness in Africa: Zimbabwe schools for the blind survey. Br $\mathcal{F}$ Ophthalmol 1993; 77: 410-2.

13 Gilbert C, Foster A. Causes of blindness in children attend ing four schools for the blind in Thailand and the Philippines. Int Ophthalmol 1993; 17: 229-34. 